\title{
Sulfuration of organoborates, an underexploited method
}

\author{
Sébastien Kerverdo and Marc Gingras* \\ Department of Chemistry, Faculty of Sciences, University of Nice-Sophia Antipolis, 28 Avenue Parc Valrose, \\ 06108 Nice Cedex 2, France
}

Received 20 March 2000; accepted 7 June 2000

\begin{abstract}
The combination of sulfurating agents with organoboranes is an underexploited synthetic transformation. The reactivity of borate complexes was investigated with several electrophilic sulfur species. Simple and practical methods for making carbon-sulfur bonds were created under almost neutral conditions. These enjoy a heavy metal-free environment and use not so toxic boron compounds. This is in contrast to the manipulation of poisonous $\mathrm{H}_{2} \mathrm{~S}$ or the use of sulfur with Grignard reagents, under highly basic and moisture-sensitive conditions. (C) 2000 Elsevier Science Ltd. All rights reserved.
\end{abstract}

Keywords: sulfuration; hypervalent elements; boron and compounds; disulfides; sulfides.

Although several methods exist for introducing sulfur into organic molecules, there is a deficiency of studies involving organoborates. ${ }^{1}$ We intend to describe here the sulfuration of these species in a heavy-metal free environment. These salts have launched new organic methodologies, due to the activation of some carbon-boron bonds. This has been exploited in many Pd-catalyzed procedures with boronic acids (Suzuki couplings), ${ }^{2}$ with aryltrifluoroborates ${ }^{3}$ or with tetraphenylborate. ${ }^{4}$ Classic examples also embrace organoborates in the sequence hydroborationoxidation, which has become a cornerstone in synthesis. As a comparison, parallel sulfur reactions are still in their infancy.

Trialkyl- or triarylboranes were sporadically used in the early sulfurations with elemental sulfur. In 1961, Mikhailov and co-workers were among the pioneers to introduce sulfuration of organoboranes with elemental sulfur. ${ }^{5}$ In 1970, other preliminary results were obtained for the direct preparation of disulfides. ${ }^{6}$ The study was confined to four substrates and the yields varied from $2-48 \%$, with only one case at $64 \%$. A speculative mechanism was proposed: the insertion of a sulfur atom into a carbon-boron bond, followed by the hydrolysis of an arylthioborane to a thiol intermediate; the latter being oxidized in situ to a disulfide. The transfer of only one boron ligand was suggested.

\footnotetext{
* Corresponding author: Fax: +33 4934404 25; e-mail: marc.gingras@wanadoo.fr 
From these mechanistic speculations, charged electron-rich species with a higher valence number would react even better with sulfur electrophiles. Our investigations started with some crystalline organoborate salts, listed in Fig. 1. Compound $\mathbf{1}$ is commercial, but we postulated that salt $\mathbf{2}$ could be generated in situ. Reagent $\mathbf{3}$ was synthesized on a multiple gram-scale, according to Vedejs and co-workers. ${ }^{7}$

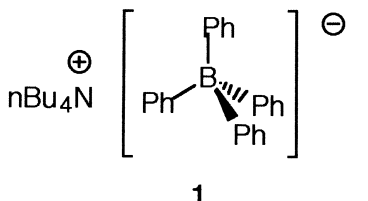

1

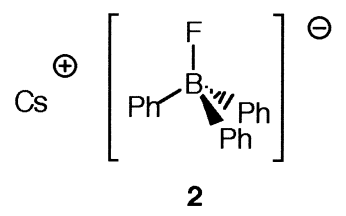

Figure 1. List of organoborates used of generated

Other reactions with organoboranes, ${ }^{8}$ less related to this work, were achieved by transfer of alkylthio groups from organic disulfides ${ }^{9}$ or by alkyl transfer from boranes to sulfenyl chlorides. ${ }^{10}$ These lead to sulfides.

The next step was to test the reactivity of electrophilic sulfur reagents, like those presented in Fig. 2. Many of them are commercial crystalline solids. The abundance of sulfur and its almost non-odorous nature, is highly attractive. As a substitute, sulfur monochloride is cheaply produced in bulk amounts. The rewards for developing new sulfuration procedures might eventually be the replacement of poisonous, smelly and gaseous $\mathrm{H}_{2} \mathrm{~S}$.

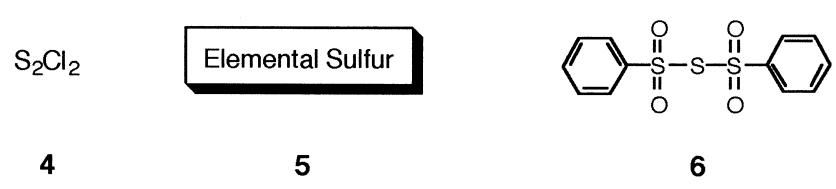

Figure 2. List of electrophilic sulfur reagents

Classic preparations of thiols and disulfides are reported in Eq. 1 (Scheme 1), from the reaction of sulfur powder with highly basic Grignard reagents. Our procedures, with inexpensive $\mathrm{S}_{2} \mathrm{Cl}_{2}$, avoid strong bases (Eq. 2). It provides an expeditive synthesis of disulfides, without an additional oxidation of thiols. In the same way, a combination of triphenylborane, $\mathrm{CsF}$ and elemental sulfur gives rise to disulfides (unoptimized, Eq. 3). In contrast to our previous work on the sulfuration of hypervalent organotins, reagent 6 selectively produces monosulfides (Eq. 4). ${ }^{11}$

Manipulation of air- and moisture-sensitive carbanions, such as Grignard reagents, is sometimes annoying. Undesirable anhydrous titrations for a standardization is also tedious. Because borate salts in Fig. 1 are either commercial, crystalline and non-hygroscopic, they are interesting synthetic equivalents to these carbanions and all procedures are operating under almost neutral conditions.

Table 1 is a compilation of assays and optimization, where we varied the following parameters: organoboron used, sulfurating agent, fluoride source, temperature and reaction time. In a general manner, tetrabutylammonium tetraphenylborate did not provide satisfactorily results either with sulfur (Entry 4: 30\% yield) or with sulfur monochloride (Entry 6: 11\% yield). In spite of several assays with 1, changes of molar ratios sulfur/boron complex and prolonged heating at $130^{\circ} \mathrm{C}$ did 


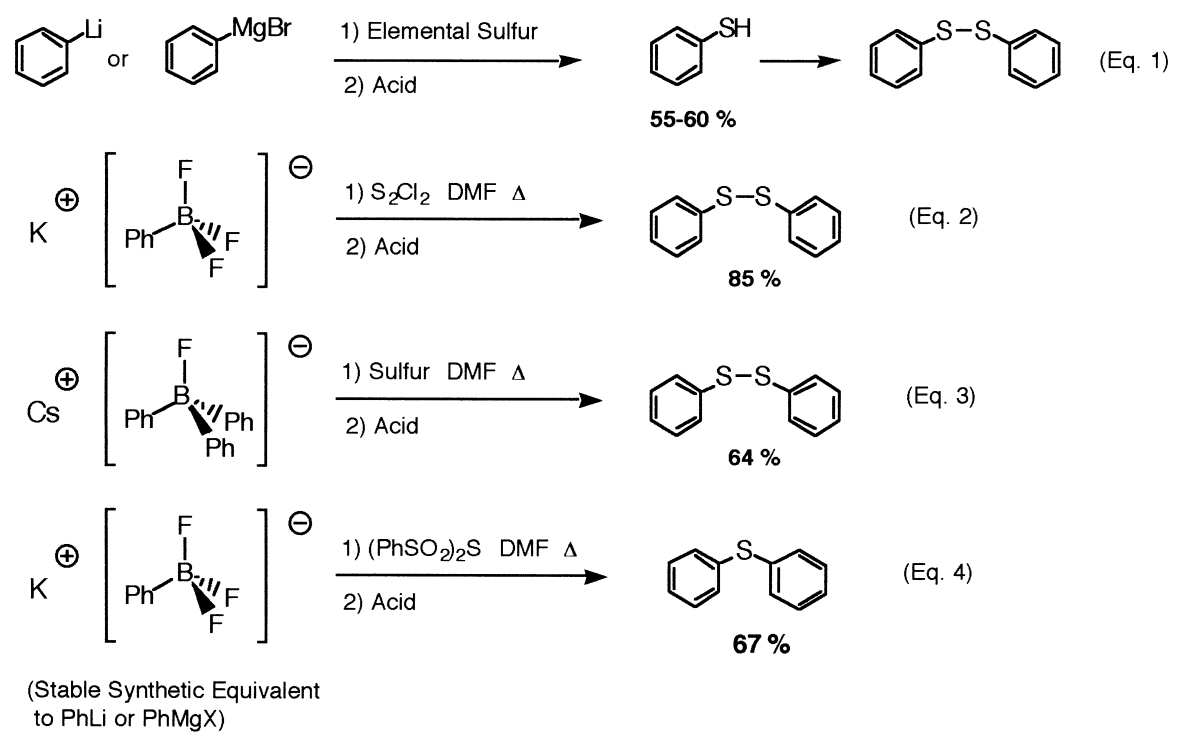

Scheme 1. Reactions of nucleophiles with sulfurating agents

not yield significant amounts of phenyl disulfide. Phenyl boronic acid was useless under similar conditions.

On the other hand, the reactivity of triphenylborane/CsF 2 and potassium phenyltrifluoroborate 3 provided the best overall results. The sulfur was somewhat troublesome, because it failed to react with 3 but gave decent yields with $\mathbf{2}$. Similarly, sulfur monochloride gave the best match with potassium phenyltrifluoroborate (Entries 11 and 12: 85 and 82\%, respectively) but a poor yield with triphenylborane/CsF 2 (Entry 3: 20\%). Finally, sulfurating agent 6 produced a reasonable yield of monosulfide with potassium phenyltrifluoroborate $\mathbf{3}$, but a minor contamination by disulfides was observed (Entries 14 and 15).

Overall, the reactions of organoborate compounds can selectively produce organic monosulfides or disulfides, depending on the electrophilic sulfur source. The efficiency varies according to the boron salts, 3 being the most reactive. Interestingly, some reactions proceed even at $50^{\circ} \mathrm{C}$, instead of $130^{\circ} \mathrm{C}$, which seems encouraging for future investigations and optimization (Entry 13). Finally, an excess of $\mathrm{S}_{2} \mathrm{Cl}_{2}$ is advisable for better yields (Entries 11 and 12) and our data suggest at this time that only one boron ligand can be transferred from $\mathbf{2}$.

At this stage, it would not be wise to delineate a precise mechanism for these sulfurations. Some divergence in the behavior of organoborates leads to postulate distinct mechanisms. One of these seems to operate in a carbanion-like manner and suggests an ionic mechanism with $\mathbf{3}$; the production of monosulfides is influencing us in this direction. ${ }^{12}$ The other mechanism is with triphenylborane complex 2 and questions the possibility of generating radicals through an $\mathrm{S}_{\mathrm{H}} 2$ reaction, leading to a final dimerization of RS. The by-product biphenyl directed us in this thought. Radical pathways with boron are known, especially in the presence of radical initiators such as oxygen. ${ }^{13}$

In summary, sulfuration of organoborates led to the controlled synthesis of sulfides or disulfides. This demonstrated the relative reactivity of tetraphenylborate, fluorotriphenylborate or phenyltrifluoroborate anions, the latter being the most reactive. Additionally, these simple methods were effected in a heavy metal-free environment, with not so toxic boron compounds. 
Table 1

Sulfuration of organoborates and boron compounds ${ }^{\mathrm{a}}$

\begin{tabular}{|c|c|c|c|c|c|c|c|}
\hline $\begin{array}{l}\text { ENTRY } \\
\text { NO }\end{array}$ & $\begin{array}{c}\text { BORON } \\
\text { COMPOUND } \\
\text { (mmol) }\end{array}$ & $\begin{array}{l}\text { SULFUR } \\
\text { REAGENT } \\
\text { (mmol) }\end{array}$ & $\begin{array}{l}\mathrm{CsF}^{\mathrm{b}} \\
\mathrm{mmol})\end{array}$ & $\mathrm{T}\left({ }^{\circ} \mathrm{C}\right)$ & TIME (hr) & \multicolumn{2}{|c|}{$\begin{array}{l}\text { PRODUCTS } \\
\text { (\% yield) }\end{array}$} \\
\hline 1 & $\mathrm{Ph}_{3} \mathrm{~B}(0.83)$ & Sulfur (2.43) & 0.99 & 130 & 10 & PhSSPh (61 \%) & $\mathrm{Ph}-\mathrm{Ph}(8 \%)$ \\
\hline 2 & $\mathrm{Ph}_{3} \mathrm{~B}(0.83)$ & Sulfur (2.43) & 0.99 & 100 & 10 & PhSSPh (9 \%) & $\mathrm{Ph}-\mathrm{Ph}(89 \%)$ \\
\hline 3 & $\mathrm{Ph}_{3} \mathrm{~B}(1.04)$ & $\mathrm{S}_{2} \mathrm{Cl}_{2}(2.13)$ & 1.04 & 130 & 7 & PhSSPh (20 \%) & \\
\hline 4 & $\left(\mathrm{nBu}_{4} \mathrm{~N}\right)\left(\mathrm{Ph}_{4} \mathrm{~B}\right)(0.40)$ & Sulfur (2.50) & $\cdots$ & 130 & 20 & PhSSPh (30 \%) & \\
\hline 5 & $\left(\mathrm{nBu}_{4} \mathrm{~N}\right)\left(\mathrm{Ph}_{4} \mathrm{~B}\right)(0.40)$ & Sulfur (1.20) & $-\cdot$ & 130 & 24 & PhSSPh (Traces) & \\
\hline 6 & $\left(\mathrm{nBu}_{4} \mathrm{~N}\right)\left(\mathrm{Ph}_{4} \mathrm{~B}\right)(0.35)$ & $\mathrm{S}_{2} \mathrm{Cl}_{2}(0.80)$ & $\cdots$ & 130 & 5 & PhSSPh (11\%) & \\
\hline 7 & $\mathrm{PhB}(\mathrm{OH})_{2}(0.82)$ & Sulfur (2.44) & 2.5 & 130 & 24 & PhSSPh (0\%) & \\
\hline 8 & $\mathrm{KPhBF}_{3}(1.09)$ & Sulfur (3.25) & -- & 130 & 17 & PhSSPh (0 \%) & \\
\hline 9 & $\mathrm{KPhBF}_{3}(0.82)$ & $\mathrm{S}_{2} \mathrm{Cl}_{2}(0.41)$ & $\cdots$ & 130 & 6 & PhSSPh (56 \%) & \\
\hline 10 & $\mathrm{KPhBF}_{3}(0.82)$ & $\mathrm{S}_{2} \mathrm{Cl}_{2}(0.45)$ & -- & 130 & 15 & PhSSPh (67 \%) & \\
\hline 11 & $\mathrm{KPhBF}_{3}(0.82)$ & $\mathrm{S}_{2} \mathrm{Cl}_{2}(0.67)$ & $\cdots$ & 130 & 16 & PhSSPh (85 \%) & \\
\hline 12 & $\mathrm{KPhBF}_{3}(0.82)$ & $\mathrm{S}_{2} \mathrm{Cl}_{2}(0.82)$ & $\cdots$ & 130 & 4 & PhSSPh (82 \%) & \\
\hline 13 & $\mathrm{KPhBF}_{3}(0.82)$ & $\mathrm{S}_{2} \mathrm{Cl}_{2}(0.82)$ & $-\cdot$ & 50 & 16 & PhSSPh (62 \%) & \\
\hline 14 & $\mathrm{KPhBF}_{3}(0.82)$ & $\left(\mathrm{PhSO}_{2}\right)_{2} \mathrm{~S}(0.45)$ & $\cdots$ & 130 & 5 & PhSPh $(67 \%)^{d} \quad F$ & PhSSPh (10\%) ${ }^{d}$ \\
\hline 15 & $\mathrm{KPhBF}_{3}(0.82)$ & $\left(\mathrm{PhSO}_{2}\right)_{2} \mathrm{~S}(0.45)$ & $\cdots$ & 50 & 16 & PhSPh (38 \%) & $\operatorname{PhSSPh}(3 \%)^{\mathrm{d}}$ \\
\hline 16 & $\mathrm{KPhBF}_{3}(0.82)$ & $\left(\mathrm{PhSO}_{2}\right)_{2} \mathrm{~S}(0.63)$ & $\cdots$ & 130 & 16 & $\operatorname{PhSPh}(80 \%)^{\mathrm{d}}$ & PhSSPh $(10 \%)^{d}$ \\
\hline $\begin{array}{l}\text { roduc } \\
\text { MF us }\end{array}$ & $\begin{array}{l}\text { ts were characterized by } \\
\text { sed as solvent }\end{array}$ & MS, & & & b: Driec & & \\
\hline
\end{tabular}

\section{Acknowledgements}

We thank the University of Nice-Sophia Antipolis for start-up funds. S.K. is grateful to the Government of France (MENRT), for a doctoral scholarship. We thank Professor Roland Fellous for allowing us to share the laboratory and for his scientific enthusiasm.

\section{References}

1. Cremlyn, R. J. An Introduction to Organosulfur Chemistry; John Wiley \& Sons: New York, 1996; 250 pp. Metzner, P.; Thuillier, A. Sulfur Reagents in Organic Synthesis; Academic Press: London, 1994; p. 200. Organosulfur Chemistry; Page, P., Ed.; Academic Press: London, 1995, p. 277. 
2. Miyaura, N.; Suzuki, A. Chem. Rev. 1995, 95, 2457-2483.

3. Darses, S.; Genêt, J.-P.; Brayer, J.-L.; Demoute, J.-P. Tetrahedron Lett. 1997, 38, 4393-4396.

4. Legros, J.-Y.; Fiaud, J.-C. Tetrahedron Lett. 1990, 31, 7453-7456.

5. Mikhailov, B. M.; Bubnov, Y. N. Izvest. Akad. Nauk S.S.S.R., Otdel. Khim. Nauk 1961, 531. Ibid Zhur. Obshchei. Kim. 1959, 29, 1648.

6. Yoshida, Z.-I.; Okushi, T.; Manabe, O. Tetrahedron Lett. 1970, 1641-1643.

7. Vedejs, E.; Chapman, R. W.; Fields, S. C.; Lin, S.; Schrimpf, M. R. J. Org. Chem. 1995, 60, 3020-3027.

8. Sulfurations: Cragg, G. M. L. In Organoboranes in Organic Synthesis; Marcel Dekker, 1973; pp. 308-310.

9. Brown, H. C.; Midland, M. M. J. Am. Chem. Soc. 1971, 93, 3291-3295.

10. Draper, P. M.; Chan, T. H.; Harpp, D. N. Tetrahedron Lett. 1970, 1688.

11. Kerverdo, S.; Fernandez, X.; Poulain, S.; Gingras, M. Tetrahedron Lett. 2000, 41, 5841-5845.

12. Vaultier, M.; Carboni, B. In Comprehensive Organometallic Chemistry; Wilkinson, G.; Stone, F. G. A.; Abel, E. W., Eds. Reactions of organoborates with electrophiles. McKillop, A. Vol. Ed.; Pergamon Press: Oxford, 1995; Vol. 11, pp. 227-234.

13. Negishi, E. In Comprehensive Organometallic Chemistry; Wilkinson, G.; Stone, F. G. A.; Abel, E. W., Eds. General discussions of the organoboron reactions. Pergamon Press: Oxford, 1982; Vol. 7, pp. 255-263. 